\title{
NEW RECORD OF THE GENUS Brulleia Szépligeti, 1904 (Hymenoptera: Braconidae: Brachistinae), WITH DESCRIPTION OF THREE NEW SPECIES FROM VIETNAM
}

\author{
Khuat Dang Long*, Dang Thi Hoa, Cao Thi Quynh Nga \\ Institute of Ecology \& Biological Resources (IEBR), VAST
}

\begin{abstract}
The genus Brulleia Szépligeti, 1904 is recorded for the first time in Vietnam, three new species, namely Brulleia flavosoma Long, sp. n.; B. mellicrus Long, sp. n. and B. nigrisoma Long, sp. n., are described and illustrated. A key to Brulleia species from the Oriental region is provided. The checklist of the already known species of the genus Brulleia is also given.

Keyswords: Braconidae, Brachistinae, Brulleiini, Brulleiina, Brulleia, new record, new species, Oriental, Vietnam.
\end{abstract}

Citation: Khuat Dang Long, Dang Thi Hoa, Cao Thi Quynh Nga, 2018. New record of the genus Brulleia Szépligeti, 1904 (Hymenoptera: Braconidae: Brachistinae), with description of three new species from Vietnam. Academia Journal of Biology, 40(4): 1-12. https://doi.org/10.15625/2615-9023/v40n4.13511.

*Corresponding author email: khuatdanglong@gmail.com

Received November 2018, accepted December 2018

\section{INTRODUCTION}

Brulleia Szépligeti, 1904 is a mediumsized genus of the subtribe Brulleiina (Hymenoptera, Braconidae, Brachistinae, Brulleiini) [Sharanowski et al. 2011, Yan et al. 2017, Chen \& van Achterberg 2019 (in. lit.)]. Up to date, the genus Brulleia comprises twenty two valid species, of which three are recorded from Australasian, four species from the Eastern Palaearctic, and sixteen species from the Oriental regions (Yu et al., 2016). So far, only one species, Brulleia obereae Chen \& van Achterberg, 1993 has been reared; it was reported as parasitoid of larvae of Oberea sp. (Coleoptera, Cerambycidae) (Chen et al., 1993).

In the previous paper published by Khuat Dang Long \& Belokobylskij (2003), only three species included in the subfamily Helconinae s.l., viz. Helcon rugodorsalis (Turner, 1919), Helconidea unicornis (Turner, 1918) and Parabrulleia shibuensis (Matsumura, 1912) were reported from
Vietnam's fauna, and in this paper part of the discoveries dealt with three new species of Brulleia from Vietnam are described and illustrated.

\section{MATERIALS AND METHODS}

Specimens studied are deposited in the Braconidae Collection of the Institute of Ecology \& Biological Resources (IEBR) at Ha Noi, Vietnam. All the types (holotypes) are kept in IEBR.

Terminology used in this paper follows van Achterberg (1993), sculpture terms are based on Harris (1979), and vein terminology follows the modified Comstock-Needham system (van Achterberg, 1993). For a key to genera of the subtribe Brulleiina see Chen et al. (1993); for additional references and data, see Yu et al. (2016). For virtually all species we used an Olympus ${ }^{\circledR}$ SZ61 binocular microscope; key to species and description of species are based on female; the measurement was carried out using an Olympus ${ }^{\circledR}$ SZ40 
binocular microscope; the photographs were made with a Sony ${ }^{\circledR}$ DSC-WX500 digital camera attached to an Olympus ${ }^{\circledR}$ SZ61 binocular microscope at IEBR. Abbreviations used in this paper are as follows: $\mathrm{POL}=$ postocellar line; $\mathrm{OOL}=$ ocular-ocellar line; $\mathrm{OD}=$ diameter of posterior ocellus; $\mathrm{MT}$ : Malaise trap; 'Hel.+number': code number indexing for specimens of the Helconinae in the collection at IEBR. NC: North Central, NE.: Northeast, NP: National Park. AMNH stands for American Museum of Natural History, and VAST stands for the Vietnam Academy of Science and Technology.

\section{RESULTS AND DISCUSSION}

\section{SYSTEMATICS}

\section{Brulleia Szépligeti, 1904}

Brulleia Szépligeti, 1904: 150; Shenefelt, 1970: 190; van Achterberg, 1983: 287; Chen et al., 1993: 378; Chou \& Hsu, 1998: 284; Yan et al., 2013: 18.

Type species. Brulleia melanocephala Szépligeti, 1904.

Diagnostic characters. Mandibles evenly curved (Figs. 3, 14, 25); maxillary and labial palpi with 2-5 and 2-3 segments, respectively; face densely reticulate-rugose (Figs. 14, 25); clypeus more or less convex or medially depressed (Figs. 3, 14, 25); occipital carina arched medio-dorsally (Fig. 2) or sometimes reduced medio-dorsally; vertex usually with longitudinal groove (Figs. 2, 13, $24)$; frons weakly concave medially or nearly flat (Fig. 2); length of hind tibia 1.6-2.0 $\times$ hind femur; second metasomal tergite usually smooth (Figs. 9, 30), rarely finely sculptured latero-basally (Fig. 18).

Host. Larvae of the Cerambycidae

Distribution. Australasian, East Palaearctic and Oriental regions

Checklist and distribution of Brulleia Szépligeti in alphabetical order

Brulleia auripes Chen \& He, 1993. Oriental: China
Brulleia brunnea van Achterberg, 983. Oriental: Indonesia

Brulleia chankaica Belokobylskij, 1996. Eastern Palearctic: Russia

Brulleia chaoi Chen \& He, 1993. Oriental: China

Brulleia fanjingensis Yan \& Chen, 2013. Oriental: China

Brulleia flavibasalis He \& Chen, 1993. Oriental: China

Brulleia flavosoma Long, sp. n.. Oriental: Vietnam

Brulleia latiannulata (Cameron, 1911). Australasian, Oriental: Indonesia, Papua New Guinea

Brulleia longipalpis Yan \& Chen, 2013. Oriental: China

Brulleia luteus $\mathrm{He}$ \& Chen, 1993. Oriental: China

Brulleia melanocephala Szépligeti, 1904. Australasian: Indonesia

B. mellicrus Long, sp. n.. Oriental: Vietnam

Brulleia nigra van Achterberg, 1983. Oriental: Indonesia

B. nigrisoma Long, sp. n.. Oriental: Vietnam

Brulleia nipponensis van Achterberg, 1983. Eastern Palearctic: Japan, Korea

Brulleia noncarinata Yan \& Chen, 2013. Eastern Palearctic: China

Brulleia obereae Chen \& van Achterberg, 1993. Oriental: China

Brulleia punctata Yan \& Chen, 2013. Eastern Palearctic: China

Brulleia rubida Chen \& He, 1993. Oriental: China

Brulleia subtilirugula $\mathrm{He} \&$ van Achterberg, 1993. Oriental: China

Brulleia taiwanensis Chou \& Hsu, 1998. Oriental: China 
Brulleia tenuipetiolata Chen \& He, 1993. Oriental: China

Brulleia townesi van Achterberg, 1983. Oriental: Philippines

\section{TAXONOMY}

\section{Key to Brulleia species from Oriental region}

1a. Maxillary palp with with 2 or $3+$ segments $\left(4^{\text {th }}\right.$ segment faintly indicated); labial palpi with 2 segments

Brulleia tricolor van Achterberg, 1983. Oriental: Philippines China.

b- Maxillary palp with 4 segments; labial palpi with 3 segments .............................................. 4

c- Maxillary palp with 5-6 segments; labial palpi with 3 segments .......................................11

2. Maxillary with 3 segments $\left(4^{\text {th }}\right.$ segment faintly indicated); median length of first metasomal tergites slender, $2.3 \times$ its apical width (Fig. 70 in van Achterberg, 1983); prepectal carina complete

Brulleia tricolor van Achterberg

- Maxillary with 2 segments; median length of first metasomal tergites shirter, median length of the tergite $1.8 \times$ its apical width (Fig. 83 in van Achterberg, 1983); prepectal carina incomplete or absent dorsally

3. Body brownish-yellow; 10th-16th antennomeres yellowish-white; fore wing vein 3-SR $1.2 \times$ as long as vein 2-SR (Fig. 87 in van Achterberg, 1983)

- Body largely black; 11th-13th antennomeres yellowish-white; fore wing vein 3-SR $1.4 \times$ as long as vein 2-SR (Fig. 79 in van Achterberg, 1983) B. melanocephala Szépligeti

4. Antenna yellow basally, blackish brown apically (Fig. 1)

- Antenna black or blackish brown with yellowish-white band submedially (F. 23) ............... 6

5. Labrum truncate ventrally (Fig. 2 in Chen et al., 1993); fore wing vein 3-SR shorter vein 2-SR (Fig. 1 in Chen et al., 1993); median length of first metasomal tergite $2.3 \times$ its apical width (Fig. 5 in Chen et al., 1993); length of hind femur $6.4 \times$ its maximum width

B. flavibasalis $\mathrm{He} \&$ Chen

- Labrum concave ventrally (Fig. 3); fore wing vein 3-SR distinctly longer vein 2-SR (Fig. 10); median length of first metasomal tergite $1.9 \times$ its apical width (Fig. 9); hind femur robust, length of hind femur $5.25 \times$ its maximum width B. flavosoma Long, sp. $\mathbf{n}$.

6. Labrum deeply concave medio-ventrally (Fig. 25; Fig. 56 in van Achterberg, 1983); body almost completely black or blackish brown (Fig. 23)

- Labrum truncate or convex (Fig. 14; Fig. 1 in Yan et al., 2013; Figs 31, 40 in van Achterberg, 1983); body dark brown or brownish-yellow ............................................. 8

7. First metasomal tergite shorter, median length $2.1 \times$ as long as its apical width; length of hind femur $6.7 \times$ its maximum width. B. nigra van Achterberg

- First metasomal tergite slender, median length $2.7 \times$ as long as its apical width (Fig. 30); length of hind femur $5.8 \times$ its maximum width; ovipositor sheath $1.6 \times$ as long as fore wing; antenna with $11^{\text {th }}-15^{\text {th }}$ antennomeres whitish yellow (Fig. 23) B. vietnamica Long, sp. $\mathbf{n}$.

8. First metasomal tergite elongate, median length of tergite $2.9-3.3 \times$ its apical width ............ 9

- First metasomal tergite shorter, median length of tergite $1.5-2.3 \times$ its apical width 10 
9. Second metasomal tergite smooth; hind wing vein $1-\mathrm{M} 1.1 \times$ as long as vein $1 \mathrm{r}-\mathrm{m}$ (Fig. 7 in Yan et al., 2013); antenna with $12^{\text {th }}-17^{\text {th }}$ antennomeres whitish yellow....

B. fanjingensis Yan \& Chen

- Second metasomal tergite sculptured (Fig. 18); hind wing vein $1-\mathrm{M} 1.7 \times$ as long as vein 1r-m (Fig. 22); antenna with $12^{\text {th }}-15^{\text {th }}$ antennomeres whitish yellow B. mellicrus Long, sp. n.

10. First metasomal tergite more or less roboust, median length of first tergite $1.5 \times$ as long as its apical width; antenna without yellowish white submedian band $\boldsymbol{B}$. townesi van Achterberg

- First metasomal tergite slender, median length of first tergite $2.1-2.3 \times$ as long as its apical width; antenna with yellowish white submedian band B. brunnea van Achterberg

11. Maxillary palp with 6 segments; labial with 3 segments ................................................. 12

- Maxillary palp with 5 segments; labial with 3 segments ...................................................... 16

12. First metasomal tergite slender, median length of first tergite $3.1 \times$ as long as its apical width (Fig. 30 in Chen et al., 1993); second tergite distinctly sculptured baso-medially; body

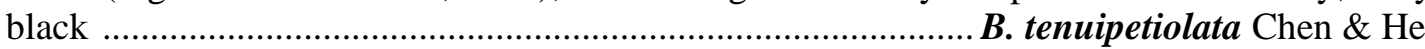

- First metasomal tergite shorter, median length of first tergite 2.0-2.2 $\times$ as long as its apical width (Figs. 40, 45, 50 in Chen et al., 1993); second tergite smooth or finely sculptured baso-laterally; body bicoloured

13. Labrum concave medio-ventrally; length of maxillary palp $1.1 \times$ as long as height of head; body black

B. longipalpis Yan \& Chen

- Labrum truncate or convex medio-ventrally; length of maxillary palp 0.5-0.7 $\times$ as long as height of head; body dark brown and yellow

14. Clypeus slightly concave; fore wing vein 3-SR equal to vein 2-SR; hind wing vein 1-M 2.0 $x$ as long as vein $1 \mathrm{r}-\mathrm{m}$; antenna yellow basally, dark brown apically ... B. auripes Chen \& $\mathrm{He}$

- Clypeus slightly straight or truncate; fore wing vein 3-SR shorter than vein 2-SR; hind wing vein 1-M 1.6-1.7 $\times$ vein 1r-m; antenna brown with yellowish-white submedian band......... 15

15. Vein 3-SR of fore wing $1.6 \times$ as long as vein 2-SR (Fig. 41 in in Chen et al., 1993); ventral margin of clypeus slightly concave; precoxal sulcus almost smooth.

B. subtilirugula $\mathrm{He} \&$ van Achterberg

- Vein 3-SR of fore wing shorter than vein 2-SR (Fig. 46 in Chen et al., 1993); ventral margin of clypeus truncate; precoxal sulcus wide and shallow, densely punctate

B. obereae Chen \& van Achterberg

16. First metasomal tergite long, median length of first tergite $3.4 \times$ as long as its apical width; second tergite sculptured baso-medially (Fig. 35 in Chen et al., 1993).....B. chaoi He \& Chen

- First metasomal tergite shorter, median length of first tergite 1.8-2.5 $\times$ as long as its apical width; second tergite smooth or slightly sculptured baso-laterally (Figs. 10, 20, 45 in Chen et al., 1993)

17. Hind femur slender, length of hind femur $8.6 \times$ as long as its maximum width (Fig. 21 in Chen et al., 1993); second tergite polished, smooth (Fig. 25 in Chen et al., 1993)

B. yangi He \& Chen

- Hind femur thicker, length of hind femur 5.0-5.8 $\times$ as long as its maximum width; second tergite more or less sculptured (Figs. 15, 20 in Chen et al., 1993). 
18. Body black or almost blackish brown; vein 1-M of hind wing $1.5-2.0 \times$ as long as vein $1 \mathrm{r}-\mathrm{m}$; clypeus recticulate-rugose B. taiwanensis Chou \& Hsu

- Body yellowish brown or reddish brown; vein 1-M of hind wing 1.2-1.3 $\times$ as long as vein 1r-m (Figs .11, 16 in Chen et al., 1993); clypeus rugose-punctate

19. Antenna yellow basally, $17^{\text {th }}$ and following antennomeres blackish brwon; second metasomal tergite widened posteriorly, sculptured baso-laterally (Fig. 20 in Chen et al., 1993)

B. lutea $\mathrm{He} \&$ Chen

- Antenna blackish brown with yellowish white submedian band $\left(8^{\text {th }}-15^{\text {th }}\right.$ antennomeres yellowish-white); second metasomal tergite quadrate, almost smooth (Figs. 10, 15 in Chen et al., 1993) B. rubida Chen and He.

\section{Brulleia flavosoma Long, sp. $\mathbf{n}$.}

Figs 1-11

Material examined. Holotype, $\hat{\sigma}$, "Hel.058" (IEBR), NE Vietnam: Tuyen Quang, Na Hang, Son Phu, forest, MT, $22^{\circ} 17 ’ 32^{\prime}$ 'N $\quad 105^{\circ} 28^{\prime} 19^{\prime \prime} \mathrm{E}, \quad 573 \mathrm{~m}$, 15.viii.2017, K. Long

Description. Body length $14.8 \mathrm{~mm}$, fore wing length $11.5 \mathrm{~mm}$ (Fig. 1).

Head. Antenna with 39 antennomeres; third antennomere $1.2 \times$ longer than fourth antennomere; length of third, fourth and penultimate antennomeres $4.25,4.0$ and $1.5 \times$ their width, respectively; preapical antennomere $0.7 \times$ as long as apical antennomere; maxillary palp 5-segmented; labial palp 3-segmented; length of maxillary palp $0.5 \times$ height of head; in frontal view, face width $1.7 \times$ as long as length of face and clypeus combined; distance between tentorial pits $0.8 \times$ distance from pit to eye margin (Fig. 3); in lateral view, transverse diameter of eye as long as temple (Fig. 4); occipital carina arched medio-dorsally (Fig. 2); in dorsal view, median length of head $1.45 \times$ as long as wide (Fig. 2); and eye subequal to temple in dorsal view; length of malar space $1.3 \times$ basal width of mandible, and $0.9 \times$ maximum width of eye (Fig. 3); ocelli large, situated in low triangle (Fig. 2); POL:OD:OOL=9:10:24; frons deeply depressed, coriaceous, striate laterally (Fig. 2 ); vertex rugose-punctate; temple sparsely punctate (Fig. 2); face coarsely rugose medially with a tubercle and triangular depression (Fig. 3); ventral clypeal margin slightly concave medially, clypeus rugose as face; labrum emarginate ventrally, with long setae, sparsely and finely punctate (Fig. 3).

Mesosoma. Length of mesosoma $1.6 \times$ as long as its height; pronotal side wide, crenulate antero-dorsally, almost smooth medially; prepectal carina absent; precoxal sulcus wide and shallow with oblique rugosities (Fig. 7); mesopleuron with sparse and fine punctures, nearly smooth; subalar space flat, smooth; mesosternum rugosepunctate; notauli crenulate anteriorly, widened and largely rugose posteriorly (Fig. 6); middle lobe of meoscutum densely and finely punctate; lateral lobes of mesoscutum sparsely punctate; scutellar sulcus rather long, $0.6 \times$ as long as scutellum, coriaceous, with one median carina (Fig. 6); scutellum sparsely punctate; propodeum with short basal carina, rugose with two transverse striae medially (Fig. 8).

Wings. Length of fore wing $3.2 \times$ its maximum width (Fig. 10); length of pterostigma $2.9 \times$ as long as wide; fore wing vein 3 -SR $2.3 \times$ vein $r$, and $0.4 \times$ vein SR1 (r:3-SR:SR1=15:35:87; 2-SR:3-SR:r $\mathrm{m}=23: 35: 24) ; 1-\mathrm{M} 1.5 \times \mathrm{m}$-cu; 1-CU1 $0.1 \times$ vein 2 -CU1 $\times(1-C U 1: c u-a: 2-C U 1=4: 14: 34)$ (Fig. 10); basal length of second submarginal cell of fore wing $2.15 \times$ its maximum width. Length of hind wing $4.2 \times$ its maximum width; vein $\mathrm{R} 1$; vein $\mathrm{M}+\mathrm{CU} 1.7 \times$ vein $1-\mathrm{M}$ $1.3 \times$ vein $1 \mathrm{r}-\mathrm{m}$; subbasal cell widened apically (Fig. 11). 

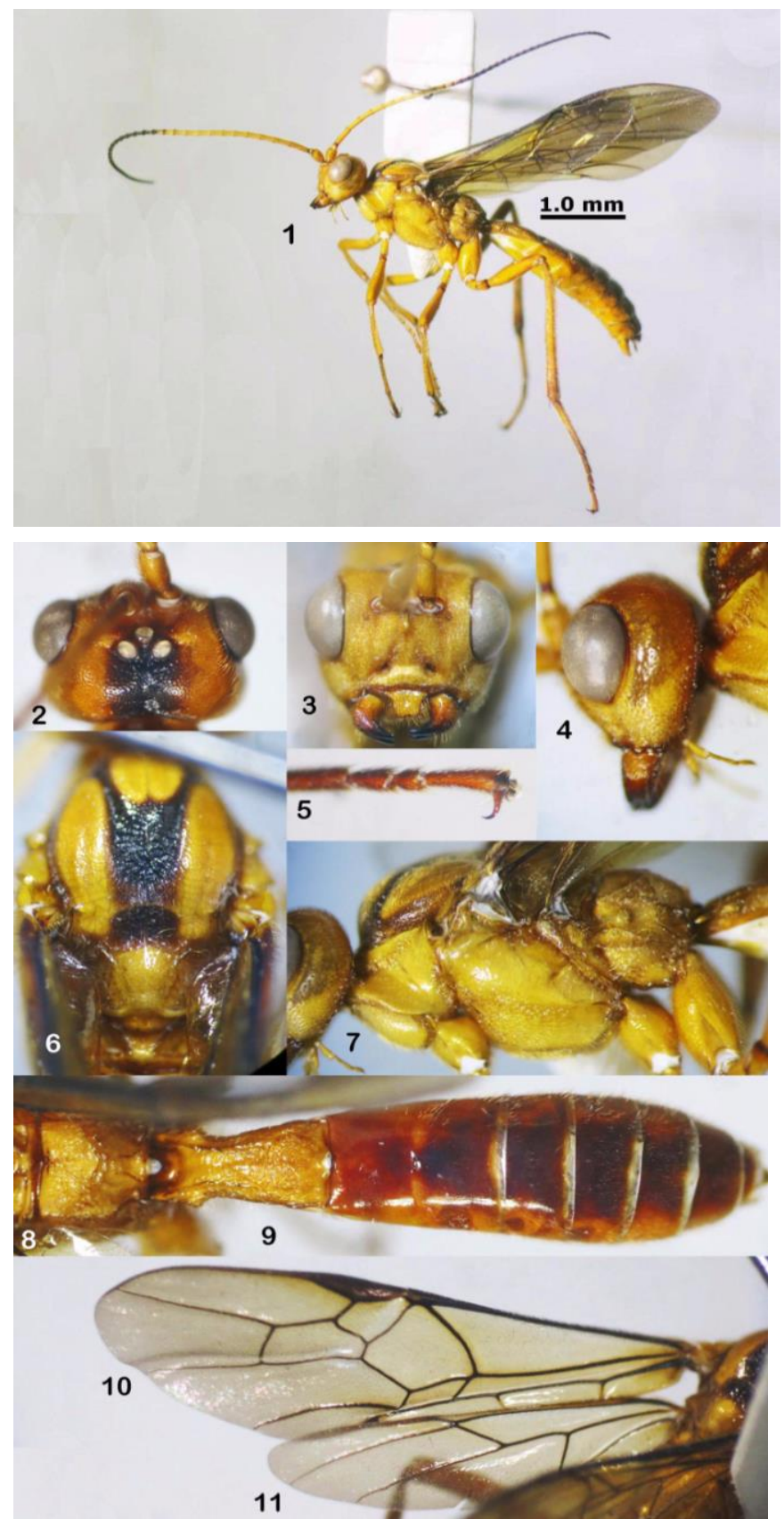

Figures 1-11. Brulleia flavosoma Long, sp. n. 1. Habitus (holotype, male), 2. Head (dorsal view), 3. Head (frontal view), 4. Head (lateral view), 5. Hind third-fifth tarsal segments, 6. Mesonotum, 7. Mesopleuron, 8. Propodeum, 9. metasoma, 10. Fore wing, 11. Hind wing

Legs. Length of hind femur, tibia and basitarsus $5.25 \times, 11.7 \times$ and $8.0 \times$ their width, respectively; hind tibia $1.85 \times$ as long as hind femur; hind tibial inner spur $0.24 \times$ hind basitarsus, and $1.1 \times$ outside spur; fourth hind tarsus $0.3 \times$ hind telotarsus (without pretarsus) (Fig. 5); hind coxa almost smooth, with sparse and fine punctures. 
Metasoma. First metasomal tergite $1.9 \times$ its apical width; suture between second and third metasomal indistinct (Fig. 9); first metasomal tergite with lateral carinae in basal 0.6 of first tergite (Fig. 9), coriaceous basally, largely rugose laterally and apically; remaining tergites smooth.

Colour. Body yellow; more than basal half of antenna yellow, dark brown apically (Fig. 1); stemmaticum and vertex medially blackish brown to black; notauli black; scutellar sulcus dark brown (Fig. 6); wings yellow with veins brown (Figs 10, 11), pterostigma yellow medially (Fig. 10); first metasomal yellow; second-sixth tergites brownish yellow (Fig. 9).

Female and host. Unknown. Quang).

Distribution. NE Vietnam (Tuyen

Etymology. From "flavus" (Latin for "yellow") and "soma" (Greek for "body"), because of the yellow body.

Notes. The new species, Brulleia flavosoma, sp. n., is distinguished from $B$. flavibasalis $\mathrm{He} \&$ Chen, from China by the characters given in the key. The new species is differs from B. nigra van Achterberg, from Philippines by having: a) Hind femur robust, $5.2 \times$ as long as its maximum width $(7.7 \times$ in B. nigra); b) Antenna without yellowish white submedian band; and c) Body yellow.

\section{Brulleia mellicrus Long, sp. n.}

Figs 12-22

Material examined. Holotype, $\widehat{\partial}$, "Hel.059" (IEBR), NC Vietnam: Ha Tinh, Huong Son, $18^{\circ} 22^{\prime} \mathrm{N} 106^{\circ} 13^{\prime} \mathrm{E}, 900 \mathrm{~m}$, May 18, 1998, Malaise, AMNH, K. Long.

Description. Body length $13.3 \mathrm{~mm}$, fore wing length $9.5 \mathrm{~mm}$ (Fig. 12).

Head. Antenna with 37 antennomeres; third antennomere $1.3 \times$ longer than fourth antennomere (13:10); length of third, fourth and penultimate segments $2.2,1.7$ and $2.0 \times$ their width, respectively; preapical antennomere $0.7 \times$ as long as apical antennomere; maxillary palp 5-segmented; labial palp 3-segmented; length of maxillary palp $0.65 \times$ height of head; in frontal view, face width $1.5 \times$ as long as length of face and clypeus combined; distance between tentorial pits $0.9 \times$ distance from pit to eye margin (Fig. 14); in lateral view, transverse diameter of eye $1.3 \times$ as long as temple (Fig. 15); occipital carina evenly concave, slightly reduced medio-dorsally; in dorsal view, median length of head $1.9 \times$ as long as wide; eye height $1.6 \times$ as long as temple in dorsal view; length of malar space $0.8 \times$ basal width of mandible, and $0.5 \times$ maximum width of eye; ocelli medium-sized in rather high triangle (Fig. 13); POL:OD:OOL=7:8:20; frons largely rugose; vertex and temple with sparse and fine punctures (Fig. 13); face reticulate-rugose, medially with a tubercle (Fig. 14); clypeus rugose, ventral clypeal margin almost straight; labrum convex ventrally, sparsely punctate; malar space foveolate-rugose.

Mesosoma. Length of mesosoma $2.1 \times$ as long as its height; pronotal side largely crenulate anterior-dorsally, with longitudinal striae ventrally, coriaceous medially, rugose posteriorly; prepectal carina incomplete; precoxal sulcus wide, largely rugose (Fig. 17); mesopleuron rugo-punctate; notauli deep, largely crenulate with median carina dividing posterior area of notauli into two parts (Fig. 16); median and lateral lobes of mesoscutum with dense punctures (Fig. 16); scutellar sulcus crenulate, with one median carina; scutellum sparsely punctate; propodeum foveolate-rugose anteriorly, areolate-rugose posteriorly (Fig. 20). 


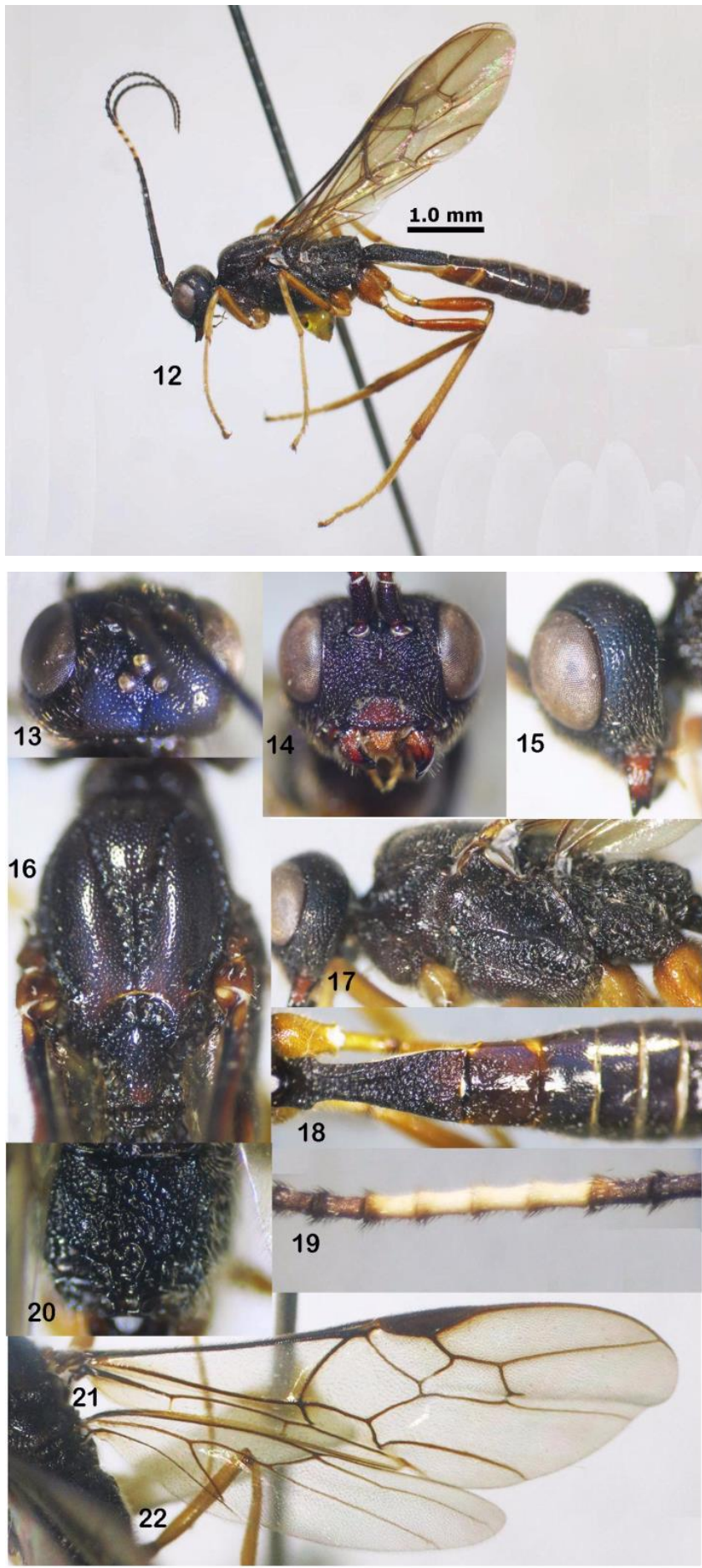

Figures 12-22. Brulleia mellicrus Long, sp. n. 12. Habitus (holotype, male), 13. Head (dorsal view), 14. Head (frontal view), 15. Head (lateral view), 16. Mesonotum, 17. Mesopleuron, 18. First-fifth metasomal tergites, 19. Median antennomeres, 20. Propodeum, 21. Fore wing, 22. Hind wing 
Wings. Fore wing (Fig. 21), length of fore wing $3.1 \times$ its maximum width; length of pterostigma $3.8 \times$ as long as wide; fore wing vein 3 -SR $1.7 \times$ vein $r$, and $0.3 \times$ vein SR 1 (r:3-SR:SR1=13:22:75); 2-SR:3-SR:r$\mathrm{m}=19: 22: 18$; vein $1-\mathrm{M} 1.25 \times$ as long as vein $\mathrm{m}-\mathrm{cu}$; vein 1-CU1 quadrate; cu-a:2CU1 $=12: 31$; vein $\mathrm{r}-\mathrm{m}$ with remnant vein (Figs 12,21 ); basal length of second submarginal cell of fore wing $2.05 \times$ its maximum width. Length of hind wing $3.9 \times$ its maximum width; vein $\mathrm{M}+\mathrm{CU} 1.3 \times$ vein $1-\mathrm{M}$; vein $1-\mathrm{M}$ $1.7 \times$ vein $1 \mathrm{r}-\mathrm{m}$; subbasal cell narrowed apically (Fig. 22).

Legs. Length of hind femur, tibia and basitarsus $5.8,12.8$ and $10.0 \times$ their width, respectively; hind tibia $1.9 \times$ as long as hind femur; hind tibial inner spur $0.24 \times$ hind basitarsus, and $1.1 \times$ as long as outside spur; hind coxa sparsely punctate latero-dorsally.

Metasoma. Length of first metasomal tergite $2.9 \times$ its apical width; median length of second tergite $1.1 \times$ third tergite; suture between second and third tergites distinct (Fig. 18); first metasomal tergite with two lateral carinae in basal 0.7 of first tergite, remainder largely rugose; second tergite finely sculptured basally, smooth apically (Fig. 18); third-sixth tergites smooth.

Colour. Body brownish brown, except first sternite yellow; antenna blackish brown with $12^{\text {th }}-15^{\text {th }}$ antennomeres whitish yellow (Figs. 12, 19); all legs yellow; wing tegula, pterostigma and veins brown; wing membrane yellowish brown.

Female and host. Unknown.

Distribution. NC Vietnam (Ha Tinh).

Etymology. From "mellosus" (Latin for "honey-colored"), and "crus" (Latin for "leg"), because of the honey yellow-coloured legs.

\section{Brulleia vietnamica Long, sp. $\mathbf{n}$.}

Figs. 23-32

Material examined. Holotype, + , "Hel.029" (IEBR), NE Vietnam: Tuyen Quang, Na Hang, Son Phu, forest, MT, $22^{\circ} 17^{\prime} 32^{\prime} ' \mathrm{~N} \quad 105^{\circ} 28^{\prime} 19^{\prime \prime} \mathrm{E}, \quad 573 \mathrm{~m}$, 25.viii.2017, K. Long.

Description. Body length $10.5 \mathrm{~mm}$, forewing length $8.0 \mathrm{~mm}$, antenna $10.3 \mathrm{~mm}$, ovipositor sheath $12.6 \mathrm{~mm}$ (Fig. 23).

Head. Antenna with 39 antennomeres; third antennomere $1.1 \times$ fourth antennomere; length of third, fourth and penultimate antennomeres 5.8, 5.2 and $1.0 \times$ their width, respectively; apical antennomeres shortened (Fig. 23a); maxillary palp 4-segmented; labial palp 3-segmented; length of maxillary palp $0.8 \times$ height of head; in frontal view, face width $1.6 \times$ as long as length of face and clypeus combined; distance between tentorial pits $0.7 \times$ distance from pit to eye margin (Fig. 25); in lateral view, eye $1.3 \times$ as long as temple (Fig. 26); occipital carina arched and interrupted medio-dorsally; in dorsal view, median length of head $0.6 \times$ as long as wide; and height of eye $1.9 \times$ as long as temple (Fig. 24); length of malar space as long as basal width of mandible, and $0.4 \times$ maximum width of eye; ocelli medium-sized in rather high triangle (Fig. 25); POL:OD:OOL=9:6.5:21; frons more or less flat, rugose medially, with convergent striae ventrally; vertex and temple finely punctate (Fig. 24); face reticulaterugose medially, foveolate-rugose laterally; ventral clypeal margin almost straight, clypeus largely rugose; labrum concave medio-ventrally (Fig. 25), with long setae, rugose-punctate.

Mesosoma. Length of mesosoma $1.85 \times$ as long as its height (Fig. 27); pronotal side sparsely crenulate anteriorly, longitudinally striate ventrally, coriaceous medially; prepectal carina present; precoxal sulcus wide, foveolate-rugose (Fig. 27); mesopleuron rugose-punctate; notauli wide and deep, largely crenulate, its posterior area wide, with median carina, prolonged and almost fused with scutellar sulcus posteriorly (Fig. 28); median lobe of mesoscutum densely punctate; middle lobe of mesoscutum largely rugose-punctate (Fig. 28); scutellar sulcus smooth, with one 
median carina (Fig. 28), and $0.45 \times$ as long as scutellum; scutellum sparsely rugosepunctate nteriorly, rugose posteriorly; propodeum with short basal median carina, largely rugose laterally, foveolate-rugose medially and posteriorly (Fig. 29).

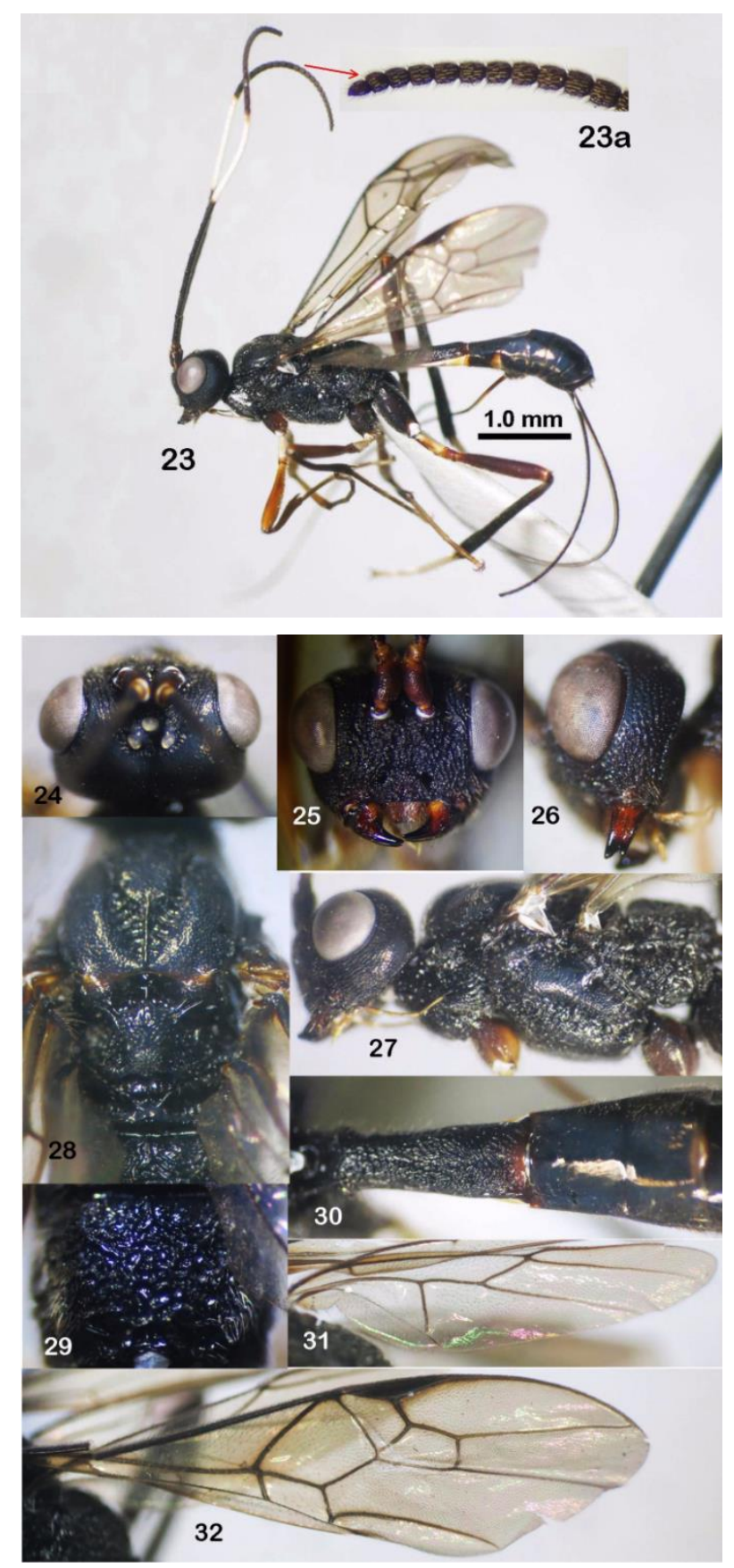

Figures 23-32. Brulleia vietnamica Long, sp. n. 23. Habitus (holotype, female), 24. Head (dorsal view), 25. Head (frontal view), 26. Head (lateral view), 27. Mesopleuron, 28. Mesonotum, 29. Propodeum, 30. First-third metasomal tergites, 31. Hind wing, 32. Fore wing 
Wings. Length of fore wing $3.2 \times$ its maximum width (Fig. 32); length of pterostigma $4.1 \times$ its width; vein 3 -SR $1.3 \times$ vein $r$, and $0.3 \times$ vein SR1 (r:2-SR:3SR:SR1:rm=9:12:16:54:11) (Fig. 33); vein 1M $1.4 \times$ vein $\mathrm{m}-\mathrm{cu}$; vein cu-a $3.0 \times 1$-CU1 (9:3), vein $1-\mathrm{CU} 1 \quad 0.15 \times$ vein 2-CU1; basal length of second submarginal cell of fore wing $2.0 \times$ its maximum width. Length of hind wing $3.6 \times$ its maximum width; vein $\mathrm{M}+\mathrm{CU} 2.0 \times 1-\mathrm{M}$; vein $1-\mathrm{M} 1.3 \times$ vein $1 \mathrm{r}-\mathrm{m}$; subbasal cell widened apically (Fig. 31).

Legs. Length of hind femur, tibia and basitarsus $5.9,13.2$ and $9.8 \times$ their width, respectively; hind tibia $1.85 \times$ as long as hind femur; hind tibial inner spur $0.3 \times$ hind basitarsus, and $1.1 \times$ as long as outside spur; hind coxa coriaceous latero-dorsally.

Metasoma. Length of first metasomal tergite $2.7 \times$ its apical width (Fig. 30); median length of second tergite $1.4 \times$ third tergite; suture between second and third metasomal tergites indistinct (Fig. 30); first metasomal tergite without lateral carinae, reticulaterugose entirely (Fig. 30); second fifth tergites smooth.

Colour. Body black; antenna black, except scapus and pedicellus infuscate brown, with $11^{\text {th }}-15^{\text {th }}$ antennomeres cream white (Fig. 23); fore and middle coxae yellowish brown; fore and middle trochanter and trochantellus pale yellow; fore and middle femurs yellow; fore and middle tibia and tarsus brownish yellow; hind coxa, femur and tibia brown; hind trochanter, trochantellus and tarsus pale yellow; tegula, pterostigma and wing veins brown; wing membrane yellowish brown; ovipositor sheath brown; first-second sternites pale yellow.

Male and host. Unknown.

Distribution. NE Vietnam (Tuyen Quang).
Etymology. The new species is named after the country of origin: Vietnam.

Acknowledgements: This research was funded by the Vietnam National Foundation for Science and Technology Development (NAFOSTED), grant No. 106-NN.052016.08. Authors express the great gratitute to Dr Kees van Achterberg, Department of Terrestrial Zoology, Naturalis Biodiversity Center Leiden (RMNH), the Netherlands for the critical comments.

\section{REFERENCES}

Belokobylskij S. A., 1996. Nine new species of Braconidae (Hymenoptera) from the Russian Far East. Journal of Natural History, 30(11): 1661-1681.

Chen X. X., He J. H., van Achterberg C., 1993. A revision of the subtribe Brulleiina van Achterberg (Hymenoptera: Braconidae: Helconinae) from China. Zoologische Mededelingen Leiden, 67(2743): 375-395.

Chen X. X, He J. H., Ma Y., 2001. Hymenoptera: Braconidae. In: Wu H, Pan CW (Eds) Insects of Tianmushan National Nature Reserve. Science Press, Beijing, 723-733 [in Chinese with English summary].

Chou L. Y., Hsu T. C., 1998. The Braconidae (Hymenoptera) of Taiwan 8. Brulleiini, Diospilini and Helconini. Journal of Agricultural Research of China, 47(3): 283-314.

Harris R. A., 1979. A glossary of surface sculpturing. Occasional Papers in Entomology, California Department of Food and Agriculture, 28: 1-33.

Long K. D., Belokobylskij S. A., 2003. A preliminary list of the Braconidae (Hymenoptera) of Vietnam. Russian Entomological Journal, 12(4): 385-398.

Long K. D., van Achterberg C., 2014. An additional list with new records of 
braconid wasps of the family Braconidae (Hymenoptera) from Vietnam. Tap chi Sinh hoc, 36(4): 397-415. https://doi.org/ 10.15625/0866-7160/v36n4.5979.

Sharanowski B. J., Dowling A. G., Sharkey M. J., 2011. Molecular phylogenetics of Braconidae (Hymenoptera: Ichneumonoidea), based on multiple nuclear genes, and implications for classification. Systematic Entomology, 36: 549-572.

Shenefelt R. D., 1970. Braconidae 2. Helconinae, Calyptinae, Mimagathidinae, Triaspinae. Hymenopterorum Catalogus (nova editio), 5: 177-306.

van Achterberg C., 1983. A revision of the new tribe Brulleiini (Hymenoptera: Braconidae). Contributions of the American Entomological Institute, 20: 281-306.

van Achterberg C., 1987. Revision of the European Helconini (Hymenoptera: Braconidae: Helconinae). Zoologische Mededelingen Leiden, 61(18): 263-285. van Achterberg C., 1993. Illustrated key to the subfamilies of the Braconidae (Hymenoptera: Ichneumonoidea). Zoologische Verhandelingen Leiden, 283: 1-189.

Yan C. J., He J. H., Chen X. X., 2013. The genus Brulleia Szépligeti (Hymenoptera, Braconidae, Helconinae) from China, with descriptions of four new species. ZooKeys 257: 17-31. https://doi.org/10.3897/zookeys.257.3832.

Yan C. J., He J. H., Chen X. X., 2017. Review of the tribe Helconini Foerster s.s. from China, with descriptions of 18 new species. Zootaxa 4291(3): 401-457. https://doi.org/10.11646/zootaxa.4291.3.1

Yu D. S., van Achterberg K., Horstmann K., 2016. Biological and taxonomical information: Ichneumonoidea 2016. Taxapad Interactive Catalogue, Ottawa. Database on flash drive. Available from https://www.taxapad.com/global.php (accessed 27 November, 2018). 